\title{
BIOMASSA MICROBIANA E ATIVIDADE ENZIMÁTICA EM SOLOS SOB VEGETAÇÃO NATIVA E SISTEMAS AGRÍCOLAS ANUAIS E PERENES NA REGIÃO DE PRIMAVERA DO LESTE (MT) $^{(\mathbf{1})}$
}

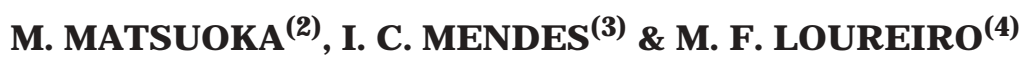

\begin{abstract}
RESUMO
Primavera do Leste é um dos pólos de produção de grãos e fibras do Mato Grosso, com lavouras altamente tecnificadas. Este estudo foi realizado num Latossolo Vermelho-Amarelo da região de Primavera, com objetivo de avaliar a biomassa e a atividade microbiana de solos sob vegetação nativa e sistemas agrícolas anuais e perenes. As amostras de solo foram coletadas em duas profundidades (0-5 e 5-20 cm), no início da estação chuvosa, em áreas sob cultivo de videira (Vitis vinifera), entrelinha e linha, cultivos anuais (soja) e em uma área de vegetação nativa de Cerradão. Foram avaliados o carbono da biomassa microbiana (СВM), carbono prontamente mineralizável e as atividades das enzimas $\beta$-glucosidase, fosfatase ácida e arilsulfatase. Nas duas profundidades avaliadas, os sistemas de uso do solo com culturas perenes e anuais apresentaram reduções médias de $70 \%$ no CBM, em relação à área sob vegetação nativa. 0 manejo diferenciado na entrelinha do parreiral e a utilização do capim-pé-degalinha (Eleusine indi ca), como cobertura viva, proporcionaram aumentos no $C$ mineralizável e na atividade das enzi mas $\beta$-glucosidase e arilsulfatase nas duas profundidades. Os níveis médios de P no solo sob Cerradão resultaram em valores de atividade da fosfatase ácida inferiores aos dos observados em outros locais do Cerrado. Mesmo assim, na profundidade de 0-5 cm, a atividade da fosfatase ácida no Cerradão foi superior à da entrelinha do parreiral (VE) e à da área com culturas anuais, demonstrando a sua importância na mineralização do fósforo orgânico em áreas sob vegetação nativa. Os resultados obtidos confirmaram a sensibilidade dos parâmetros microbiológicos e bioquímicos para identificar alterações no solo de acordo com os diferentes sistemas de uso da terra.
\end{abstract}

Termos de indexação: carbono da biomassa, $\beta$-glucosidase, fosfatase ácida, arilsulfatase, respiração microbiana, Cerrado, soja, parreiral.

\footnotetext{
(1) Parte da Tese de Mestrado em Agricultura Tropical da primeira autora, apresentada à Universidade Federal de Mato Grosso UFMT. Recebido para publicação em abril de 2002 e aprovado em março de 2003.

(2) Engenheira-Agrônoma, Universidade Federal de Mato Grosso - UFMT. Av. Fernando Corrêa s/n, CEP 78060-900 Cuiabá (MT). E-mail: mmatsu@terra.com.br

(3) Pesquisadora da Embrapa Cerrados. Caixa Postal 08223, CEP 73301-970 Planaltina (DF). E-mail: mendesi@cpac.embrapa.br

(4) Professora do Departamento de Fitotecnia e Fitossanidade, UFMT. Bolsista do CNPq. E-mail: Ioureiromf@uol.com.br
} 


\title{
SUMMARY: MICROBIAL BIOMASS AND ENZYME ACTIVITIES IN SOILS UNDER NATIVE VEGETATION AND UNDER ANNUAL AND PERENNIAL CROPPING SYSTEMS AT THE PRIMAVERA DO LESTE REGION - MATO GROSSO STATE
}

\begin{abstract}
Primavera do Leste is one of the most important farming areas of Mato Grosso State. This study was carried out in a Red-Yellow Latosol to evaluate the mi crobial biomass and enzymeactivities in soils under native vegetation (known as "Cerradão") and in soils under annual and perennial cropping systems. Soil samples werecollected, at thebeginning of the rainy season, at two depths $(0-5$ and $5-20 \mathrm{~cm})$ in areas under a vineyard (row and between rows), annual crops (soybean) and native vegetation. The parameters evaluated were soil microbial bi omass carbon (MBC), readily mineralizabl ecarbon (microbial respiration) and thesoil enzymes $\beta$-gl ucosi dase, acid phosphataseand aryl sul fatase. In relation to thenative area, at thetwo depths reductions of up to $70 \%$ in theM BC wereobserved in theannual and perennial cropping systems. The soil management conducted in the area between therows of thevineyard along with thepresenceof thegrass E leusine indica, as a cover crop, favored an increase in the levels of readily mineralizable carbon, and the $\beta$-glucosidase and arilsulfataseactivities. TheP content of thesoil under Cerradão, at thetwo depths, reduced the levels of acid phosphataseactivities as compared to other places of the Cerrados region. Neverthel ess, at the $-5 \mathrm{~cm}$ depth the phosphataseactivity of theCerradão area was greater than in the annual crops, showing the importance of this enzyme on organic $P$ cycling in nati ve ecosystems. Theresul ts confirmed the sensi bi lity of mi crobi ol ogi cal and biochemical parameters to evaluate changes that occurred in soil as a consequence of different management systems.
\end{abstract}

Index terms: biomass carbon, $\beta$-glucosidase, acid phosphatase, arylsulfatase, microbial respiration, Cerrado, soybean, vineyards.

\section{NTRODUÇÃO}

O estado de Mato Grosso apresenta-se com grande destaque no cenário agrícol a nacional, sendo a região de Primavera do Leste um dos pólos de produção de grãos e fibras do Estado, com lavouras altamente tecnificadas, as quais produzem soja, al godão, milho e arroz, além de al gumas frutíferas. Em Primavera do Leste, a viticultura éuma atividade em expansão, consistindo numa alternativa para diversificação agrícola, com grande possibilidade para desenvolver-se e estabel ecer-se no estado. Estudos rel ativos a determi nações das propriedades biológicas do solo, nessas áreas, são importantes para avaliar a sustentabilidade dos diferentes agroecossistemas da região.

As propriedades biológi cas e bioquímicas do solo, tais como: a atividade enzimática, a taxa de respiração, a diversidade e a biomassa microbiana, são indicadores sensíveis que podem ser utilizados no monitoramento de alterações ambientais decorrentes do uso agrícola, sendo ferramentas para orientar o planejamento e a avaliação das práticas de manejo utilizadas (Turco et al ., 1994; Santana \& Bahia Filho, 1998; Doran \& Parkin, 1996).

A microbiota do solo é a principal responsável pela decomposição dos resíduos orgânicos, pela ciclagem de nutrientes e pel ofluxo de energia dentro do solo, exercendo influência tanto na transformação da matéria orgânica, quanto na estocagem do carbono e nutrientes minerais () enkinson \& Ladd, 1981). Entretanto, determinações da biomassa não fornecem indicações sobre os níveis de atividade das populações microbianas do solo, sendo importante também avaliar parâmetros que estimem a atividade microbiana, tais como: oC prontamentemineralizável e a atividade enzimática, para verificar o estado metabólico das comunidades de microrganismos do solo (Oliveira, 2000).

Apesar do crescente interesse em aspectos relacionados com o funcionamento biol ógico do solo sob sistemas naturais e agrícolas, estudos sobre o impacto de diferentes sistemas de manejo na biomassa e atividade microbiana dos solos de Cerrado são recentes (Renz,1997; Mendes et al., 1999; Oliveira et al., 1999; Carneiro, 1999; Carneiro et al., 1999; Oliveira, 2000; Mendes \& Vivaldi, 2001; Oliveira et al., 2001; Mendes, 2002).

O objetivo deste trabal ho foi avaliar a biomassa ea atividade microbiana de um Latossolo VermelhoAmarelo, na região de Primavera do Leste(MT), sob vegetação nativa, cultivos anuais e perenes.

\section{MATERIAL E MÉTODOS}

O estudo foi realizado na Fazenda J uriti, município de Dom Aquino (MT), a $70 \mathrm{Km}$ de 
Primavera do Leste (MT) pela BR 070, onde foram coletadas amostras de solo no início do período chuvoso (novembro de 2000), em três áreas diferentes: uma área sob vegetação nativa de Cerradão, utilizada, como referência, para as determinações das propriedades microbiológicas e bi oquímicas do solo, e duas outras áreas com cultivos de videira (Vitis vinifera) e soja (Glycinemax).

O sol o das três áreas era um Latossol o Vermel hoAmarelo distrófico, característico das bordas do Planalto dos Guimarães, de textura franco-argiloarenosa. As propriedades químicas do sol o nas três áreas são apresentadas no quadro 1 e foram determinadas segundo métodos descritos pela EMBRAPA (1997).

\section{Caracterização das áreas}

As três áreas eram adjacentes e foram divididas em duas parcelas de $30 \times 40 \mathrm{~m}$ de onde foram col etadas, aleatoriamente, 20 subamostras de solo por parcela nas profundidades de $0-5$ e $5-20 \mathrm{~cm}$. A coleta foi realizada por meio da abertura de trincheiras de $30 \mathrm{~cm}$ de profundidade, retirando-se, com auxílio de uma espátula, fatias de solo na profundidade de $0-5 \mathrm{~cm}$ e, posteriormente, de $5-20 \mathrm{~cm}$. Na área sob vegetação nativa, antes da coleta das amostras, procedia-se à remoção da serapilheira presente na superfície do solo.

\section{Área I}

Constituída de um sistema de cultivo perene formado por um vinhedo de 1 ha do cultivar Patrícia enxertado sobre IAC-572, com cinco anos de idade, em período de frutificação (maturação das bagas).

$O$ vinhedo foi instalado em sistema de latada com espaçamento de 2,3 m entre plantas e 2,5 m entrelinhas. O plantio foi irrigado por aspersão subcopa e, quando da implantação do parreiral, a área foi calcareada ( $3 \mathrm{t} \mathrm{ha}^{-1}$ ) sendo realizadas anualmente, na entrelinha, adubações demanutenção com macronutrientes (700 g de superfosfatosimples, $500 \mathrm{~g}$ de cloreto de potássio e $200 \mathrm{~g}$ de uréia por planta) e micronutrientes ( $25 \mathrm{~g}$ de FTE BR-12 por planta). Semestralmente, foram aplicados, como adubação orgânica, resíduos desoja, milho e algodão (2 t ha-1), distribuídos na linha e entrelinha. Durante a col eta das amostras de solo, o capim-pé de-gal inha (Eleusineindica) estava sendo utilizado, nas entrelinhas, como cobertura viva.

As col etas desol o foram realizadas nas entrelinhas (VE) e nas linhas de plantio (VL).

\section{Área II}

A segunda área de coleta consistiu de um cultivo anual (CA) com seis hectares de soja. Essa área foi cultivada com soja no sistema plantio direto por cinco anos consecutivos (de 1993 a 1998), intercalados com duas safrinhas de milho (1996/97) e uma de milheto (1998). Nas safras de 1998/99 e 1999/00, foi instalado oal godão, cultivar Ita 90, em plantio di reto. Na safra de 2000/2001, a área foi cultivada com soja, cultivar Conquista semeada em 20/10/2000, sob preparo convencional de solo (uma aração e duas gradagens). A soja foi semeada numa densidade de 17 plantas por metro e num espaçamento de $45 \mathrm{~cm}$.

As col etas desol oforam realizadas nas entrelinhas da soja

\section{Área III}

A terceira área estava localizada perpendicularmenteàs Áreas I ell, e consistindo em uma faixa de três hectares sob vegetação nativa, do tipo Cerradão, formada por espécies arbóreas com 8 a $15 \mathrm{~m}$ de altura, com predominância de aroeira (Schinus terebinthifolius) e jatobá (Hymenaea sp.).

Quadro 1. Propriedades químicas de um Latossolo Vermelho-Amarelo da região de Primavera do Leste (MT), sob três sistemas de uso do solo, nas profundidades de 0-5 e 5-20 cm

\begin{tabular}{|c|c|c|c|c|c|}
\hline Sistema de uso do solo & $\mathbf{p H ~} \mathbf{H}_{2} \mathrm{O}$ & Al & $\mathrm{Ca}+\mathrm{Mg}$ & $\mathbf{P}$ & $\mathbf{K}$ \\
\hline & & \multicolumn{2}{|c|}{$\mathrm{mmol}_{\mathrm{c}} \mathrm{dm}^{-3}$} & \multicolumn{2}{|c|}{$\mathrm{mg} \mathrm{dm}^{-3}$} \\
\hline & \multicolumn{5}{|c|}{ Profundidade de $0-5 \mathrm{~cm}$} \\
\hline Videira entrelinha (VE) & 6,85 & 0,0 & 69,4 & 669,55 & 829,50 \\
\hline Videira linha (VL) & 6,90 & 0,0 & 64,4 & 670,95 & 475,50 \\
\hline Culturas anuais (CA) & 6,50 & 0,40 & 31,4 & 7,35 & 105,00 \\
\hline \multirow[t]{2}{*}{ Cerradão } & 4,80 & 16,8 & 4,0 & 29,55 & 39,00 \\
\hline & \multicolumn{5}{|c|}{ Profundidade de $5-20 \mathrm{~cm}$} \\
\hline Videira entrelinha (VE) & 6,50 & 0,0 & 77,3 & 422,30 & 275,00 \\
\hline Videira linha (VL) & 6,60 & 0,0 & 55,6 & 108,40 & 187,00 \\
\hline Culturas anuais (CA) & 6,30 & 0,4 & 30,4 & 8,25 & 139,50 \\
\hline Cerradão & 4,75 & 13,3 & 2,3 & 12,75 & 33,00 \\
\hline
\end{tabular}




\section{Preparo das amostras}

As amostras de solo foram homogeneizadas e acondicionadas em sacos plásticos, sendo armazenadas em geladeira (7 a $10 \stackrel{\circ}{ } \mathrm{C}$ ), durante uma semana, quando foram iniciados os ensaios. A determinação da umidade do solo foi efetuada pel o método gravimétrico, secando-se as amostras em estufa a $100{ }^{\circ} \mathrm{C}$ por $72 \mathrm{~h}$, antes e depois da limpeza dos resíduos vegetais.

Antes do peneiramento e limpeza (visando à remoção cuidadosa de resíduos de plantas e raízes), por causa do el evado teor de umidade (>35\%), as amostras de solo foram expostas ao ar, em temperatura ambiente, por duas horas.

\section{Análises microbiológicas e bioquímicas}

Foram avaliadas cinco propriedades biológicas: carbono da biomassa microbiana (CBM), carbono prontamentemineralizável eatividades das enzimas $\beta$-glucosidase, fosfatase ácida earilsulfatase. Todas essas análises foram realizadas no laboratório de Microbiologia do Solo da Embrapa-Cerrados, Planaltina (DF).

\section{Carbono da biomassa microbiana (CBM)}

Utilizou-se o método Clorofórmio-F umigaçãoI ncubação (CFI), proposto por J enkinson \& Pol wson (1976), no qual a biomassa microbiana é estimada com base na diferença do fluxo de $\mathrm{CO}_{2}$ de amostras de solo fumigadas com clorofórmio $(F)$ e não fumigadas (NF). A pós a col eta no campo, o teor de umi dade das amostras ( $20 \mathrm{~g}$ ) foi ajustado para $80 \%$ da capacidade de retenção de água (equivalente a $80 \%$ do teor de $\mathrm{H}_{2} \mathrm{O}$ retido no solo a $6 \mathrm{kPa}$ ). Posteriormente, as amostras foram pré-incubadas no escuro, por sete dias, em temperatura ambiente $\left(26^{\circ} \mathrm{C}\right)$. No quinto dia da pré-incubação, metade das amostras foi fumigada por $48 \mathrm{~h}$ em um dessecador acoplado a uma bomba de vácuo, que continha uma placa de Petri com $25 \mathrm{~mL}$ de clorofórmio isento de álcool. Duranteeste período, as amostras NF foram mantidas em temperatura ambiente. Após a fumigação, o cloroformi o foi retirado do dessecador e possíveis resíduos, nas amostras fumigadas, foram el iminados por meio de quatro evacuações real izadas com uma bomba de vácuo.

Após a operação de evacuação, as amostras $F$ e NF foram transferidas para recipientes herméticos (500 mL decapacidade), contendo um frasco de vidro com $10 \mathrm{~mL}$ de $\mathrm{KOH} 0,3 \mathrm{~mol} \mathrm{~L}^{-1}$, e incubadas no escuro, por dez dias, em temperatura ambiente. A quantidade de $\mathrm{CO}_{2}$ liberada do solo foi determinada após titulação com $\mathrm{HCl} 0,1 \mathrm{~mol} \mathrm{~L}^{-1}$ usando fenolftaleína 1 \% como indicador. Antes da titulação, foram adicionados $3 \mathrm{~mL}$ de $\mathrm{BaCl}_{2} 20 \%$. O carbono na biomassa foi determinado pela diferença entre o $\mathrm{CO}_{2}$ evoluído das amostras $\mathrm{F}$ e NF , no período de 10 dias após a fumigação, utilizando-se um fator de correção (Kc) de 0,41 (Anderson \& Domsch, 1978). As determinações de bi omassa foram realizadas com base em três repetições analíticas (três fumigadas e três nãofumigadas) por amostra de solo coletada no campo.

\section{Carbono prontamente mineralizável}

O carbono prontamente mineralizável do sol o foi estimado por meio da quantidade de $\mathrm{CO}_{2}$ liberado do solo não fumigado durante o período de 17 dias de incubação. Foram realizadas duas titulações neste período: a primeira, aos setedias, ea segunda, aos dezessete dias do início da incubação das amostras. Para cada período de incubação, utilizouse, como controle, a quantidade de $\mathrm{CO}_{2}$ presente em um frasco sem solo, que continha um reci pientecom

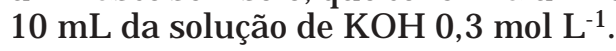

\section{Atividade enzi mática do solo}

Foram avaliadas as atividades de enzimas do solo associadas ao ciclo do carbono ( $\beta$-glucosidase); do fósforo (fosfatase ácida) e do enxofre (arilsulfatase), utilizando-se os métodos descritos por Tabatabai (1994). Esses métodos baseiam-sena determinação colorimétrica do p-nitrofenol (coloração amarela) formado após a adição de substratos incolores específicos para cada enzima avaliada. Para cada amostra de solo, coletada no campo, foram efetuadas três repetições analíticas nolaboratório. A atividade enzimática do solo foi expressa em $\mu \mathrm{g}$ p-nitrofenol liberado por grama de solo seco por hora.

\section{Análises estatísticas}

Como se trata de um estudo de comparação de sistemas em nível de fazenda, realizado em áreas manejadas de forma homogênea, as áreas I, II e III foram divididas em duas parcelas de $30 \times 40 \mathrm{~m}$, constituindo os dados apresentados a média dessas parcelas. Para quantificar a variabilidade espacial das propriedades biológicas e bioquími cas avaliadas, para cada sistema de uso do solo, foi calculado o desvio-padrão das médias das duas parcelas. Em cada parcela, as amostras compostas de sol o foram feitas com 20 subamostras, visando à redução do erro experimental.

\section{RESULTADOS E DISCUSSÃO}

Em relação ao Cerradão, nos sistemas de cultivo perene (VE, VL) eanual (CA), houve, respectivamente, reduções do carbono da biomassa mi crobiana (CBM), na profundidade de $0-5 \mathrm{~cm}$, de 68,66 e $75 \%$, e, na profundidade de $5-20 \mathrm{~cm}$, de 61,73 e $75 \%$ (Quadro 2). Reduções na biomassa microbiana de solos de cerrado sob uso agrícola em relação à vegetação nativa também foram observadas por Maciel et al. (1996), Mendes et al. (1999); Mercante et al. (2000), Oliveira (2000) e Mendes (2002). 
No estudo realizado por Oliveira (2000), na região de Planaltina (DF), num Latossolo VermelhoAmarelo de Cerrado com culturas anuais contínuas, foram observadas, na profundidade de $0-5 \mathrm{~cm}$, reduções médias no CBM, em relação às áreas nativas, de $52 \%$, independentemente das épocas de avaliação (estação seca ou chuvosa). Nas áreas sob vegetação nativa, dentre os fatores responsáveis por condições mais favoráveis à biomassa microbiana, destacam-se: ausência de preparo do solo e maior diversidade florística (Bandick \& Dick, 1999). Além de favorecer a preservação das hifas fúngicas e o acúmulo da serapilheira na superfície do solo (propiciando a ocorrência de menor variação e de níveis mais adequados de temperatura e umidade), a ausência de revolvimento do sol o também resulta em maior presença de raízes, as quais aumentam a entrada de substratos carbonados no sistema, via exudatos radiculares (Bopaiah \& Shetti, 1991). A diversi dade florística das áreas nativas ea presença de vegetação durante todo o ano influenciam a produção (quantidade) ea qualidade da serapilheira. O somatório desses fatores contribui para a ocorrência de maiores níveis de biomassa nessas áreas, comparativamente às ár eas sob cultivo.

Nas áreas sob cultivo, além das reduções no CBM, também foram observadas reduções nos teores de matéria orgânica do sol o (Quadro 2). Em relação à área nativa, as reduções na matéria orgânica na profundidade de 0-5 cm foram, respectivamente, de 8 , 32 e $38 \%$, para os sistemas de cultivo perene, VE e VL eanual (CA). Na profundidade de $5-20 \mathrm{~cm}$, as reduções nos teores de matéria orgânica foram de 12,47 e $39 \%$, para VE, VL e CA, respectivamente. Como as reduções nos teores de CBM foram mais acentuadas que as reduções da matéria orgânica, os resultados mostram que o carbono da biomassa microbiana, que representa a parte viva e mais ativa da matéria orgânica do solo, é mais sensível à remoção da cobertura vegetal nativa quea partenão viva da matéria orgânica. Por essa razão, o CBM tem sido apontado por vários autores (Dick, 1994;
Bal ota et al., 1998; Mendes \& Vivaldi, 2001; Mendes, 2002) como um indicador de qualidade, com sensibilidade para detectar modificações no solo, antes mesmo que os teores de matéria orgânica sejam alterados significativamente.

Nos quadros 2 e 3, observa-se que, nas duas profundidades avaliadas, a entrelinha do sistema de cultivo perene (VE) apresentou níveis de C prontamente mineralizável ede atividade da enzima $\beta$-glucosidase mais el evados que os dos demais sistemas de uso do solo (VL, CA e Cerradão). Esse resultado pode estar relacionado com o uso de restos culturais de soja, milho e algodão, como cobertura morta, na entrelinha do parreiral, e com o efeito rizosférico do capim-pé-de-galinha (Eleusineindica), utilizado como cobertura viva, proporcionando maior entrada de C prontamente mineralizável, em relação aos demais sistemas.

A $\beta$-glucosidase atua na etapa final do processo de decomposição da celulose. Essa enzima é responsável pela hidrólise dos resíduos de cel obiose formando o açúcar simples $\beta$-D-gl ucose (Tabatabai, 1994; Paul \& Clark, 1996). Sendo a celobiose um dissacarídeo de rápida decomposição no solo, sua presença poderia explicar a relação entre os teores el evados de atividade da $\beta$-glucosidase e os teores de $C$ prontamente mineralizável, observados na entrelinha do parreiral (VE). A menor quantidade de $\mathrm{C}$ prontamente mineralizável, na área sob Cerradão, pode ser um reflexo da maior diversidade de espécies vegetais e, conseqüentemente, da maior complexidade do resíduos vegetais que atingem a superfície do solo (galhos, ramos, fol has, flores, frutos e sementes).

À exceção da área sob culturas anuais (CA), em todas as demais áreas avaliadas, os maiores val ores de C prontamente mineralizável foram observados na profundidade de $0-5 \mathrm{~cm}$ (Quadro 2). I sto pode ser atribuído ao acúmulo de resíduos vegetais, na superfície do solo, estimulando a atividade microbiana, determinada pela liberação de $\mathrm{CO}_{2}$. Embora a área de culturas anuais estivesse sob o

Quadro 2. Carbono da biomassa microbiana, C prontamente mineralizável e matéria orgânica de um L atossolo Vermelho-Amarelo da região de Primavera do Leste (MT), sob três sistemas de uso do solo, nas profundidades de 0-5 e $5-20 \mathrm{~cm}$

\begin{tabular}{|c|c|c|c|c|c|c|}
\hline \multirow{2}{*}{ Sistema de uso do solo } & \multicolumn{2}{|c|}{ C da biomassa microbiana } & \multicolumn{2}{|c|}{ C prontamente mineralizável } & \multicolumn{2}{|c|}{ Matéria orgânica } \\
\hline & $0-5 \mathrm{~cm}$ & $5-20 \mathrm{~cm}$ & $0-5 \mathrm{~cm}$ & $5-20 \mathrm{~cm}$ & $0-5 \mathrm{~cm}$ & $5-20 \mathrm{~cm}$ \\
\hline & \multicolumn{4}{|c|}{$\mathrm{mg} \mathrm{kg}^{-1} \mathrm{C}$ no solo } & \multicolumn{2}{|c|}{$\mathrm{g} \mathrm{kg}^{-1}$} \\
\hline Videira entrelinha (VE) & $124,0 \pm 60,5$ & $163,5 \pm 47,9$ & $306,5 \pm 44,9$ & $152,4 \pm 24,3$ & $33,0 \pm 0,0$ & $31,5 \pm 3,7$ \\
\hline Videira linha (VL) & $132,4 \pm 60,7$ & $112,7 \pm 3,8$ & $194,9 \pm 70,7$ & $30,1 \pm 17,0$ & $24,6 \pm 3,0$ & $18,6 \pm 0,4$ \\
\hline Culturas anuais (CA) & $96,8 \pm 16,6$ & $104,1 \pm 50,7$ & $130,3 \pm 32,0$ & $96,0 \pm 8,2$ & $22,3 \pm 1,8$ & $21,3 \pm 0,4$ \\
\hline Cerradão & $391,6 \pm 166,7$ & $420,9 \pm 79,0$ & $215,2 \pm 25,6$ & $59,5 \pm 28,8$ & $36,2 \pm 5,2$ & $35,1 \pm 0,0$ \\
\hline
\end{tabular}


Quadro 3. Atividade enzimática de um Latossolo Vermelho-Amarelo da região de Primavera do Leste (MT), sob três sistemas de uso do solo, nas profundidades de 0-5 e 5-20 cm

\begin{tabular}{|c|c|c|c|c|c|c|}
\hline \multirow{2}{*}{ Sistema de uso do solo } & \multicolumn{2}{|c|}{$\beta$-GIucosidase } & \multicolumn{2}{|c|}{ F osfatase ácida } & \multicolumn{2}{|c|}{ Arilsulfatase } \\
\hline & $0-5 \mathrm{~cm}$ & $5-20 \mathrm{~cm}$ & $0-5 \mathrm{~cm}$ & $5-20 \mathrm{~cm}$ & $0-5 \mathrm{~cm}$ & $5-20 \mathrm{~cm}$ \\
\hline & & & $\mu \mathrm{g}$ p-nitrofen & $\mathrm{g}^{-1}$ solo $\mathrm{h}^{-1}$ & & - \\
\hline Videira entrelinha (VE) & $78,1 \pm 0,6$ & $72,3 \pm 12,2$ & $318,2 \pm 6,5$ & $322,4 \pm 43,3$ & $54,8 \pm 11,5$ & $85,2 \pm 11,5$ \\
\hline Videira linha (VL) & $41,0 \pm 10,0$ & $19,4 \pm 4,2$ & $290,6 \pm 79,2$ & $183,5 \pm 2,2$ & $33,8 \pm 5,5$ & $14,4 \pm 1,8$ \\
\hline Culturas anuais (CA) & $51,9 \pm 6,9$ & $59,8 \pm 6,6$ & $280,5 \pm 11,8$ & $342,5 \pm 3,3$ & $16,6 \pm 0,9$ & $20,5 \pm 0,2$ \\
\hline Cerradão & $47,2 \pm 6,3$ & $29,2 \pm 6,0$ & $383,1 \pm 39,3$ & $262,4 \pm 1,5$ & $99,1 \pm 17,1$ & $84,6 \pm 18,6$ \\
\hline
\end{tabular}

sistema plantio direto desde 1993, na safra de 2000/ 2001, o preparo do solo foi efetuado com aração e gradagem (preparo convencional), resultando na incorporação dos restos culturais no perfil do solo, diminuindo as diferenças entre as profundidades de 0-5 e 5-20 cm.

Alvarez et al . (1995); Bal ota et al . (1998); Mendes et al. (1999) e Vargas \& Scholles (2000), avaliando a produção de $\mathrm{C}-\mathrm{CO}_{2}$ sob diferentes sistemas de manejo, também observaram que, nos sistemas de preparo convencional, a liberação de $\mathrm{C}-\mathrm{CO}_{2}$ tende a ser uniforme na profundidade de $0-20 \mathrm{~cm}$. Em sistemas de plantio direto e com preparo reduzido do solo, os maiores níveis de liberação de $\mathrm{C}-\mathrm{CO}_{2}$ ocorrem na camada superficial.

As menores quantidades de $\mathrm{C}$ prontamente mineralizável e de atividade da $\beta$-glucosidase, observadas na profundidade de $5-20 \mathrm{~cm}$ nas amostras coletadas na linha do parreiral (VL) e na área sob Cerradão (Quadro 3), podem ser uma conseqüência da maior complexidade dos resíduos vegetais nessa profundidade do solo (maior quantidade de raízes lignificadas), acarretando uma menor entrada de resíduos carbonados de rápida decomposição.

$\mathrm{Na}$ profundidade de $0-5 \mathrm{~cm}$, a atividade da fosfataseácida do Cerradão (383,1 $\mu \mathrm{g}$ p-nitrofenol g${ }^{1}$ de sol o $^{-1}$ ) foi superior à da entrelinha do parreiral (VE) e à da área com culturas anuais (Quadro 3). Isso demonstra a importância dessa enzima na mineralização do fósforo orgânico nas áreas sob vegetaçãonativa, ondea matéria orgânica éa principal fonte de nutrientes para o crescimento das plantas.

Considerando o el evado desvio-padrão observado na linha do parreiral (VL), nãofoi observada diferença na atividade da fosfatase entre essa área e o Cerradão. O el evado desvio-padrão na linha do parreiral podeestar relacionado com a capina manual para controle de invasoras, interferindo na distribuição do adubo fosfatado. Ainda na profundidade de $0-5 \mathrm{~cm}$, verificou-se que a atividade da fosfatase na entrelinha (VE) foi ligeiramente superior à do sistema com culturas anuais (CA). Na profundidade de $5-20 \mathrm{~cm}$, as maiores atividades da fosfatase ocorreram na entrelinha do parreiral (VE) e na área sob culturas anuais. A linha do parreiral (VL) apresentou os menores valores de atividade dessa enzima.

Os val ores de atividade da fosfataseáci da na área sob Cerradão em Primavera do Lesteforam menores que os valores reportados por Mendes \& Vivaldi (2001) numa área de Cerradão localizada em Planaltina (DF). Num estudo sobreas propriedades microbiológicas de sol os sob diferentes fitofisionomias do bioma Cerrado, esses autores observaram em amostras col etadas num Cerradão, na época chuvosa e na profundidade de $0-5 \mathrm{~cm}$, valores médios de atividade da fosfatase de $2.421 \mu \mathrm{g}$ p-nitrofenol g-1 de sol o $\mathrm{h}^{-1}$. Os menores val ores de fosfatase observados no Cerradão de Primavera do Leste podem estar relacionados com os teores de fósforo presentes no solo, 30 e $13 \mathrm{mg} \mathrm{dm}^{-3}$, nas profundidades de 0-5 e 5-20 cm, respectivamente (Quadro 1). De acordo com Sousa \& Lobato (1996), para sol os de textura franco-argilo-arenosa, esses teores são considerados médios. Na área de Cerradão, avaliada no trabalho de Mendes \& Vivaldi (2001), os teores de P no Latossolo Vermel ho-E scuro argiloso eram muito baixos (inferiores a $3 \mathrm{mg} \mathrm{dm}^{-3}$ ). No presente estudo, os níveis de $\mathrm{P}$ no solo nativo sob Cerradão, nas profundidades de 0-5 e 5-20 cm, indicam que o melhor estado nutricional desse solo diminuiu a dependência do sistema com relação à ciclagem do P orgânico pela atividade da fosfatase ácida, resultando em menores níveis de atividade dessa enzima. Chunderova \& Zubeta (1969), citados por Dick (1994), também observaram reduções nos níveis de atividade da fosfatase ácida de acordo com o aumento do $\mathrm{P}$ na solução do solo. As diferenças na textura do solo no Cerradão de Primavera (LV franco-argiloso) e no Cerradão do DF (LE argiloso) também podem ter influenciado a atividade da fosfatase nas duas áreas, pois, conforme verificado 
por Sarkar et al . (1989) e Renz, (1997), a adsorção de enzimas extracelulares (tais como a fosfatase) a partículas de argila, é um importante mecanismo de estabilização e proteção contra proteases existentes na solução do solo.

Embora as adubações realizadas no parreiral tenham el evado bastante os teores de $\mathrm{P}$ no solo (>100 $\mathrm{mg} \mathrm{dm}^{-3}$, Quadro 1), as diferenças entre a atividade da fosfatasenessa área (linha eentrelinha) e na área com culturas anuais (teores de $\mathrm{P}<10 \mathrm{mg} \mathrm{dm}^{-3}$ ) não foram muito acentuadas. I sso pode estar relacionado com a aplicação localizada do adubo fosfatado no parreiral, fazendo com que o mesmo fique concentrado em locais específicos, diminuindo o efeito inibitório sobre a fosfataseácida. E mbora os teores de P na área sob culturas anuais seja menor, o adubo fosfatado éincorporado ao solo, o que também resulta na inibição dessa enzima. De qualquer forma, conforme também observado por Dick (1994), fica evidenciada a dificuldade de estabelecer correlações entre a bioquímica e a química do solo em áreas onde a entrada de nutrientes via adubação é el evada.

No quadro 3, são apresentados os valores de atividade da enzima arilsulfatase. Nas duas profundidades, o Cerradão apresentou atividades

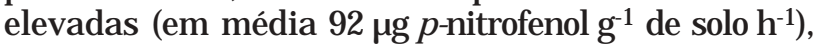
evidenciando a importância da ciclagem do enxofre orgânico pela arilsulfatase nas áreas nativas. Oliveira (2000) observou que a atividade da arilsulfatase em um sistema com culturas anuais foi 1,6 vez menor que o de uma área nativa de Cerrado, na profundidade de $0-5 \mathrm{~cm}$. Entretanto, na profundidade de 5-20 cm, não foram observadas diferenças entre as duas áreas.

Nas áreas sob uso agrícola, na profundidade de 0-5 cm, a linha e a entrelinha do parreiral (VE e VL) apresentaram níveis de atividades da arilsul fatase superiores aos da área sob cultivo anual. Como os ânions $\mathrm{H}_{2} \mathrm{PO}_{4}^{-} \mathrm{e} \mathrm{SO}_{4}^{-}$competem entre si pel os mesmos síti os de adsorção nos colóides do solo, e como $\mathrm{O} \mathrm{H}_{2} \mathrm{PO}_{4}$ - é adsorvido preferencialmente nesses sítios (Tisdale et al., 1993), as maiores atividades da arilsulfatase no parreiral podem estar associadas a uma deficiência de $\mathrm{S}$ acarretada pelos altos teores de $\mathrm{P}$ nessas áreas (VE eVL, Quadro 1), estimulando a atividade da arilsulfatase. $\mathrm{Na}$ profundidade de $5-20 \mathrm{~cm}$, a entrelinha do parreiral (VE) apresentou níveis deatividade da arilsul fatase semel hantes aos da área de Cerradão e superiores aos das amostras col etadas na linha do parreiral (VL) e na área sob culturas anuais (CA). Esse resultado pode estar associado ao efeito rizosférico do capimpé-de-galinha, presente nas entrelinhas, semel hante ao observado com o $\mathrm{C}$ prontamente mineralizável e com a $\beta$-glucosidase. Conforme discutido para a profundidadede $0-5 \mathrm{~cm}$, tambémé possível que oelevado teor de P da entrelinha (Quadro 1) tenha acarretado um estímulo adicional na atividade da arilsulfatase.
O presente estudo constitui o primeiro relato sobre as propriedades microbiológicas de solos sob cultivo e sob vegetação nativa no estado de Mato Grosso. Apesar de as determinações terem sido efetuadas apenas com amostras coletadas no início da época chuvosa, foram avaliados alguns dos agroecossistemas mais representativos da região de Primavera do Leste. Na entrelinha do parreiral, o uso de práticas de manejo diferenciadas ea presença da gramínea Eleusineindica, como cobertura viva, influenciaram as propriedades microbiológicas do solo, aumentando o C mineralizável e a atividade das enzimas $\beta$-glucosidase e arilsulfatase. Confirmando observações de outras partes do mundo (Gupta \& Germida ,1988; Singh \& Singh, 1995) e do Brasil (Maciel et al., 1996, Mendes et al., 1999; Mercante et al., 2000; Oliveira, 2000), também foi verificada uma acentuada redução no carbono da biomassa microbiana nas áreas sob cultivo, bem como maior sensibilidade desseindicador, em relação à matéria orgânica, na quantificação do impacto da conversão deáreas nativas para sistemas agrícolas.

Com relação à fosfatase ácida, as diferenças observadas nos valores de atividade em Primavera do Leste e nos estudos de Mendes \& Vivaldi (2001) na região do DF demonstram a importância dos estudos locais para o melhor entendimento do funcionamento biológico dos solos de Cerrado. No contexto do crescente interesse que os estudos de biol ogia do sol o têm adquirido nos últimos anos e da possibilidade do uso de indicadores microbiológicos e bioquímicos para avaliar o impacto de sistemas de manejo que melhoram ou degradam a qualidade do solo, esse resultado merece destaque, visto que evidencia a importância da formação de bancos de dados locais, usando, como referencial, áreas nativas próximas aos agroecossistemas avaliados. Conforme destacado por Oliveira et al. (2001), a utilização de métodos padronizados de coleta, preparo e análises das amostras de solo será fundamental para comparação dos resultados obtidos nos diferentes locais.

\section{CONCLUSÕES}

1. Os sistemas de uso do solo com culturas perenes e anuais reduzem o carbono da biomassa mi crobiana, em relaçãoa áreas sob vegetação nativa.

2. Práticas demanejo diferenciadas, na entrelinha do parreiral, e a presença da gramínea Eleusine indica, como cobertura viva, influenciam as propriedades microbiológicas do solo, aumentando o C mineralizável e a atividade das enzimas $\beta$ glucosidase e arilsulfatase.

3. O carbono da biomassa microbiana, o carbono prontamente mineralizável e as atividades das enzimas $\beta$-gl ucosidase, fosfatase ácida earilsulfatase 
são indicadores biológi cos sensíveis para identificar alterações no solo de acordo com os diferentes sistemas de uso da terra.

\section{AGRADE CIMENTOS}

Os autores agradecem ao proprietário e aos funcionários da Fazenda J uriti/Primavera do Leste (MT), pelo apoio nas coletas; aos funcionários do laboratório de Microbiologia do Solo da Embrapa Cerrados: EmílioJ . Taveira, Maria das Dores Silva, OdeteJ . dos Santos, Osmar Teago Oliveira eVilderete Castro Alves, pelo valioso auxílio nas análises laboratoriais, e à CAPES, pela concessão de bolsa. Projeto realizado com recursos do PCOPG/CN Pq.

\section{LITE RATURA CITADA}

ALVAREZ, R.; DIAZ, R.A.; BARBERO, N.; SANTANATOGLIA O.J . \& BLOTTA, L. Soil organic carbon, microbial biomass and $\mathrm{CO}_{2}-\mathrm{C}$ production from three tillage systems. Soil Till. Res., 33:17-28, 1995.

ANDERSON, J.P. \& DOMSCH, K.H. A physiological method for the quantitative measurement of microbial biomass in soils. Soil Biol. Biochem., 10:215-221, 1978.

BALOTA, E.L.; COLOZZI-FILHO, A.; ANDRADE, D.S. \& HUNGRIA, M. Biomassa microbiana e sua atividade em solos sob diferentes sistemas de preparo e sucessão de culturas. R. Bras. Ci. Solo, 22:641-649, 1998.

BANDICK, A.K. \& DICK, R.P. Field management effects on soil enzymes activities. Soil Biol. Biochem., 31:1471-1479, 1999.

BOPAIAH, B.M. \& SHETTI, H.S. Soil microflora and biological activities in the rhizospheres and root regions of coconutbased multistoreyed cropping and coconut monocropping systems. Soil Biol. Biochem., 17:297-302, 1991.

CARNEIRO, R.G. Dinâmica de parâmetros biológicos associados ao cicl o do fósforo em sol o de cerrado sob diferentes sistemas de manejo. Santa Catarina, UniversidadeF ederal de Santa Catarina, 1999. 86p. (Tese de Mestrado)

CARNEIRO, R.G.; MENDES, I.C.; LOVATO, P.E. \& CARVALHO, A.M. Dinâmica de variáveis biológicas associadas ao ciclo do fósforo em solo de cerrado sob diferentes sistemas de manejo. Planaltina, EMBRAPA Cerrados, 1999. 5p. (Pesquisa em Andamento, 36)

CHUNDEROVA, A.I. \& ZUBETA, T. Phosphatase activity in dernopodzolic soils. Pochvovendenie, 11:47-53, 1969.

DICK, R.P. Soil enzymes activities as indicators of soil quality. In: DORAN, J.W.; COLEMAN, D.C.; BEZDICEK, D.F. \& STEWART, B.A., eds. Defining soil quality for a sustainable environment. Madison, Soil Science Society of America, 107-124, 1994. (Special Publication, 35)

DORAN, J.W. \& PARKIN, T.B. Defining and assessing soil quality. In: DORAN, J .W.; CELEMAN, D.C.; BEZDICEK, D.F. \& STEWART, B.A., eds. Defining soil quality for sustainable environment. Madison, Soil Science Society of America, 3-21, 1994. (Special Publication, 35)
EMPRESA BRASILEIRA DE PESQUISA AGROPECUÁRIA EMBRAPA. Serviço Nacional de Levantamento e Conservação do Solo. Manual de análises de solo. 2.ed. Rio de J aneiro, 1997. 212p.

GUPTA, V.V.S.R. \& GERMIDA, J J . Distribution of microbial biomass and its activity in different soil aggregate size classes as affected by cultivation. Soil Biol. Biochem., 20:777-786, 1988.

JENKINSON, D.S. \& LADD, J.N. Microbial biomass in soil: measurement and turnover. In: PAUL, E.A. \& LADD, J .N., eds., Soil Biol. Biochem., 5:415-471, 1981.

JENKISON, D.S. \& POLWSON, D.S. The effect of biocidal treatment on metabolism in soil. V. A method of measuring soil biomass. Soil Biol. Biochem., 8:209-213, 1976.

MACIEL, M.M.F.; MELO, W.J .; CHELLI, R.A. \& LEITE, S.A.S. Biomassa microbiana de solos sob vegetação de cerrado e diferentes usos agrícolas em Planaltina (DF). In: CONGRESSO LATINO AMERICANO DO SOLO, 13., Águas de Lindóia. Anais. Águas de Lindóia, Sociedade Brasileira de Ciência do Solo, 1996. CD-ROM

MENDES, I.C. I mpactos de sistemas agropecuários na atividade enzimática e biomassa microbiana dos solos de Cerrado. In: II CONGRESSO BRASILEIRO DE SOJ A I MERCOSOJ A 2002, 2., Foz do I guaçu, 2002. Anais. Londrina, Embrapa Soja, 2002. p.246-257. (E mbrapa Soja. Documentos, 180)

MENDES, I.C.; CARNEIRO, R.G.; CARVALHO, A.M.;VIVALDI L. \& VARGAS, M.A.T. Biomassa C e atividade microbiana em solos de cerrado sob plantio direto e plantio convencional. Planaltina, EMBRAPA Cerrados, 1999. 5p.(Pesquisa em Andamento, 5)

MENDES, I.C. \& VIVALDI, L. Dinâmica da biomassa eatividade microbiana em uma área sob Mata de Galeria na região do DF. In: RIBEIRO, J .F.; SILVA, J .C.S. \& LAZARINI, C.E., eds. Conservação e recuperação da biodiversidade das Matas de Galeria do bioma Cerrado. Planaltina, EMBRAPA Cerrados, 2001. p.665-687.

MERCANTE, F.M.; GUIMARÃES, J .B.R.; MANJ ABOSCO, A.D.; SOARES, A.S.; BRAGA, A.C.A. \& ALMEIDA, K.A. Alterações na biomassa microbiana do solo submetido a diferentes sistemas de manejo e rotações/sucessões de culturas. In: REUNIÃO BRASILEIRA DE FERTILIDADE DO SOLO E NUTRIÇÃO DE PLANTAS, 24.; REUNIÃO BRASILEIRA SOBRE MICORRIZAS, 8.; SIMPÓSIO BRASILEIRO DE MICROBIOLOGIA DO SOLO, 6.; REUNIÃO BRASILEIRA DE BIOLOGIA DO SOLO, 3., Santa Maria, 2000. Anais. Santa Maria, Sociedade Brasileira de Ciência do Solo/Sociedade Brasileira de Microbiologia, 2000. CD-ROM

OLIVEIRA, J .R.A. O impacto de sistemas integrados de lavouras e pastagens na biomassa-C e na atividade biológica de um Latossolo Vermelho-Escuro de Cerrado. Brasília, Universidade de Brasília, 2000. 115p. (Tese de Mestrado)

OLIVEIRA, J .R.A.; MENDES, I.C.; VILELA, L.; VIVALDI, L. \& VARGAS, M.A.T. Carbono da biomassa microbiana e atividade biológica em solos sob sistemas integrados de culturas anuais e pastagens. Planaltina, 1999. 3p. (Pesquisa em Andamento, 35) 
OLIVEIRA, J .R.A.; MENDES, I.C. \& VIVALDI, L. Carbono da biomassa microbiana em solos de cerrado sob vegetação nativa e sob cultivo: avaliação dos métodos fumigaçãoincubação e fumigação-extração. R. Bras. Ci. Solo, 25:863871, 2001.

PAUL, E.A. \& CLARK, F.E. Soil microbiology and biochemistry. San Diego, Academic Press, 1996. 340p.

RENZ, T. Influence of land use on microbial parameters and phosphatase activity in Cerrado oxisols. Bayreuth, University Bayreuth, 1997. 72p. (Tese de Mestrado)

SARKAR, J .; LEONOWICZ, A. \& BOLLAG, J .M. Immobilization of enzymes on clays and soils. Soil. Biol. Biochem., 21:223230, 1989.

SOUSA, D.M.G. \& LOBATO, E. Correção do solo e adubação da cultura da soja. Planaltina, EMBRAPA Cerrados, 1996. 30p. (Circular Técnica, 33)

SANTANA, D.F. \& BAHIA-FILHO, A.F.C. Soil quality and agricultural sustainability in the Brazilian Cerrado. In: WORLD CONGRESS OF SOI L SCIENCE, 16., Montpellier, França. Proceedings. Montpellier, ISS, 1998. CD-ROM
SINGH, S. \& SINGH, J.S. Microbial biomass associated with water-stable aggregates in forest, savanna and cropland soils of a seasonally dry tropical region, Indian. Soil Biol. Biochem. 27:1027-1033, 1995.

TABATABAI, M.A. Soil enzymes. In: WEAVER, R.W.; SCOTT, A. \& BOTTOMELEY, P.J ., eds. Methods of soil analysis: microbiological and biochemical properties. Madison, Soil Science Society of America, 1994. p.778-835. (Special Publication, 5)

TISDALE, S.; NELSON, W.L.; BEATON, J .D. \& HAVLIN, J .H. Soil fertility and fertilizers. New York, Macmillan Publishing Company, 1993. 634p.

TURCO, R.F.; KENNEDY, A.C. \& J AWSON, M.D. Microbial indicators of soil quality. In: DORAN, J.W.; COLEMAN, D.C.; BEZDICEK, D.F. \& STEWART, B.A., eds. Defining soil quality for a sustainable environment. Madison, Soil Science Society of America, 1994. p.73-90.(Special Publication, 35)

VARGAS, L.K. \& SCHOLLES, D. Biomassa microbiana e produção de $\mathrm{C}-\mathrm{CO}_{2}$ e N mineral de um Podzólico VermelhoEscuro submetido a diferentes sistemas de manejo. R. Bras.Ci. Solo, 24:35-42, 2000. 